J. Lake Sci. (湖泊科学), 2014, 26(4):552-558

http: //www. jlakes.org. E-mail : jlakes@niglas.ac.cn

(C) 2014 by Journal of Lake Sciences

\title{
新疆博斯腾湖水体颗粒和溶解有机碳的季节变化及其来源初探
}

\author{
王秀君 ${ }^{1,2}$, 房传苓 ${ }^{1,3}$, 于志同 ${ }^{1,3}$, 王家平 ${ }^{1,3}$, 彭冬梅 ${ }^{1,3}$, 康静静 1,3 \\ (1: 中国科学院新疆生态与地理研究所荒漠与绿洲生态国家重点实验室,乌鲁木齐 830011) \\ ( 2 : 美国马里兰大学地球科学交叉学科中心, 马里兰州 20740) \\ (3: 中国科学院大学, 北京 100049)
}

\begin{abstract}
摘 要: 在博斯腾湖选取了 13 个点位,于 2012 年 5、8、10 月测定表层和底层水体中的颗粒有机碳、溶解有机碳、颗粒有机 氮和叶绿素 $\mathrm{a}$ 含量. 结果显示颗粒和溶解有机碳在表层水体中的浓度与底层相近. 博斯腾湖水体中颗粒有机碳的季节变 化十分明显, 其平均浓度从春季 $(0.64 \mathrm{mg} / \mathrm{L})$ 到夏季 $(0.71 \mathrm{mg} / \mathrm{L})$ 变化不大,但在秋季变化十分显著( 浓度达 $1.58 \mathrm{mg} / \mathrm{L}$ ). 其中西北湖区和湖心区颗粒有机碳的季节变化最明显,东部湖区颗粒有机碳的季节变化相对较小. 博斯腾湖水体的颗粒 有机碳在春、秋两季主要来自外源输人, 在夏季受水体中浮游生物的影响较大. 博斯腾湖水体中溶解有机碳也具有一定 的季节变化, 夏季浓度 (平均为 $9.3 \mathrm{mg} / \mathrm{L}$ ) 略低于春、秋两季 (平均为 $10.3 \mathrm{mg} / \mathrm{L}$ ). 溶解有机碳在河口区的季节变化最强, 其夏季浓度明显偏低, 主要是由于开都河河水的稀释作用. 总体上,博斯腾湖水体中溶解有机碳浓度的变化主要受外部 因素的影响.
\end{abstract}

关键词: 颗粒有机碳;溶解有机碳; 季节变化;博斯腾湖; 来源

\section{Seasonal variations and sources of particulate and dissolved organic carbon in Lake Bo- sten, Xinjiang Province}

WANG Xiujun ${ }^{1,2}$, FANG Chuanling ${ }^{1,3}$, YU Zhitong ${ }^{1,3}$, WANG Jiaping ${ }^{1,3}$, PENG Dongmei ${ }^{1,3}$ \& KANG Jingjing ${ }^{1,3}$

(1: Key Laboratory of Ecology and Desert Environment, Xinjiang Institute of Ecology and Geography, Chinese Academy of Sciences, Urumqi 830011, P. R. China)

(2: Earth System Science Interdisciplinary Center, University of Maryland, College Park, Maryland 20740, USA)

(3: University of Chinese Academy of Sciences, Beijing 100049, P. R. China)

Abstract: In this paper, we evaluated the seasonal variations of particulate and dissolved organic carbon and explored their sources in Lake Bosten. Water samples were collected at 13 sampling sites during May, August and October in 2012. Particulate organic carbon(POC), dissolved organic carbon(DOC), particulate organic nitrogen (PON) and chlorophyll-a concentrations were analyzed. On average, the POC concentration in the autumn $(1.58 \mathrm{mg} / \mathrm{L})$ was 2.2 times and 2.5 times of that in the $\operatorname{summer}(0.71 \mathrm{mg} / \mathrm{L}) \mathrm{and}$ spring $(0.64 \mathrm{mg} / \mathrm{L})$, respectively. Larger seasonal variation of POC was found in the northwest and central areas whereas eastern lake revealed relatively small seasonal variation of POC. External sources were responsible for the variability of POC in the spring and autumn, but plankton made a considerable contribution to POC in the summer. Overall, the concentration of DOC was lower in the summer than that in the spring and autumn. The average DOC concentration for the whole lake was about $10.3 \mathrm{mg} / \mathrm{L}$ in the spring and autumn and $9.3 \mathrm{mg} / \mathrm{L}$ in the summer. Unlike POC, DOC showed the largest seasonal change in the river mouth and the smallest change in the central area of the lake. The contribution of allochthonous organic carbon to DOC was probably much bigger than that of autochthonous organic carbon in Lake Bosten.

Keywords: Particulate organic carbon; dissolved organic carbon; seasonal variation; Lake Bosten; source

* 中国科学院“百人计划”项目 (0972021001) 和国家重点基础研究发展计划“973” 项目 (2010CB951001) 联合资助. 2013 - 10-11 收稿;2013-12-26 收修改稿. 王秀君(1962 ), 女,博士,研究员;E-mail:wwang@ essic. umd. edu. 
湖泊作为内陆水体的重要组成部分, 与陆地生态系统发生强烈的物质和能量交换, 具有较高的生产 力 $^{[1-2]}$. 同时,湖泊是流域内物质的主要汇集场所,其生态系统中的生物化学过程活跃, 是区域碳循环不可忽 视的一部分 ${ }^{[3]}$. 湖水中浮游植物通过光合作用吸收 $\mathrm{CO}_{2}$, 将其同化为有机物质. 这一过程不仅为湖泊生态系 统提供物质基础, 同时也降低了湖水表面的 $\mathrm{CO}_{2}$ 浓度, 体现了湖泊的碳汇功能. 另一方面,浮游生物在吸收利 用光合产物的同时,将同化的碳以有机形态储存于湖泊水体中,这些生物化学过程反映了湖泊的储碳功能. 由此可见,有机碳在湖泊碳循环中起到十分重要的作用.

水体中的有机碳主要以溶解有机碳 (DOC) 和颗粒有机碳 (POC) 的形式存在 ${ }^{[4-5]}$. 其中 DOC 占较大比 例, 是水体中的主要有机碳库 ${ }^{[6]}$, 其组成十分复杂, 包括各类可溶性腐殖酸、富里酸以及碳水化合物. POC 虽 然仅占总有机碳的 $10 \%$ 左右,却起着人们所熟知的 “生物葲” 的作用 ${ }^{[7]}$, 其组成可分为生命部分与非生命部 分, 其中生命部分包括微型浮游生物、大型藻类以及细菌、噬菌体; 非生命部分包括浮游生物的残体及其非 溶解性代谢产物和来自水体以外的颗粒有机碳.

国内外学者在不同地区对湖泊水体 DOC 的含量、空间分布及季节变化等方面进行了研究, 取得了一定 的进展. 研究发现, 湖泊水体中 DOC 的浓度具有一定的时空变化规律 ${ }^{[8-12]}$.一般来说,湖泊中 DOC 在冬季垂 直方向上分布较均匀; 在较深的湖泊中, 夏季表层水体中 DOC 含量比下层水体高, DOC 在深层水体中含量 基本保持不变. 国内外有关湖泊水体中 POC 的研究相对较少,已有的研究显示, POC 浓度变化具有明显的季 节性 ${ }^{[9,11,13]}$. 如红枫湖水体中 POC 在夏季的含量明显高于秋季 ${ }^{[14]}$. 湖泊水体中有机碳的时空变化在很大程 度上受其来源的影响 ${ }^{[9,12]}$.

博斯腾湖是中国最大的内陆淡水湖, 为干旱区湖泊的典型代表. 目前已有的关于博斯腾湖的研究仅限 于湖水质量评价、浮游植物和浮游动物生物量等方面 ${ }^{[15-20]}$, 有关博斯腾湖水体中有机碳方面的研究很少 ${ }^{[21]}$. 本研究拟通过春、夏、秋 3 个季节的观测, 对博斯腾湖水体 POC 和 DOC 的季节变化进行分析, 并结合 POC 与 颗粒有机氮 (PON) 的比值及与叶绿素 a ( Chl. a ) 等的关系, 对主要湖区有机碳的来源进行初步探索, 以期为 研究干旱区湖泊碳循环提供科学依据.

\section{1 研究区概况与研究方法}

\section{1 研究区概况}

博斯腾湖位于新疆焉耆盆地最洼处, 分为大、小两个湖区. 大湖区是湖体的主要部分, 东西长达 $55 \mathrm{~km}$, 南北平均宽 $20 \mathrm{~km}$, 平均水深为 $7.5 \mathrm{~m}$, 最深为 $16 \mathrm{~m}$. 在水位达 $1048 \mathrm{~m}$ 时, 水面面积为 $1210 \mathrm{~km}^{2}$, 容积为 $90 \times$ $10^{8} \mathrm{~m}^{3}$. 湖区深居欧亚大陆中心, 光照充足, 热量丰沛, 空气干燥, 雨量稀少, 为强烈内陆荒漠气候. 湖区多年 平均降水量为 $68 \mathrm{~mm}$, 年蒸发量为 $1800 \sim 2000 \mathrm{~mm}$.

博斯腾湖的水源包括开都河、黄水沟、清水河等,其中只有开都河为常年性河流 (图 1). 开都河发源于天 山, 由冰雪融水补给, 是天山南坡水量最丰富的河流之一. 开都河在宝苏浪木处分为东、西两支, 东支注人博 斯腾湖大湖, 西支注人博斯腾湖小湖. 博斯腾湖出流汇人孔雀河. 1983 年博斯腾湖西葲站投人运行以来, 孔 雀河口被封堵,大湖水通过西洜站扬水输人孔雀河, 小湖水通过达吴提闸流人孔雀河 ${ }^{[22]}$.

\section{2 样品采集}

本研究将博斯滕湖大湖区分为 4 个湖区:黄水沟区、河口区、湖心区和东部湖区,共选取 13 个点位 ( 图 1). 分别于 2012 年春季 (5 月)、夏季 (8 月) 和秋季 (10 月) 对湖水的表层 (水面下 $0.5 \mathrm{~m}$ )、底层 (距湖底 $0.5 \mathrm{~m}$ ) 各取样 $2 \mathrm{~L}$. 同时收集开都河表层水样. 所有水样均由 Nisikin 采水器收集, 然后用预先灼烧 $\left(450^{\circ} \mathrm{C}\right.$, 灼 烧 $4 \mathrm{~h})$ 过的 $\mathrm{GF} / \mathrm{F}(0.7 \mu \mathrm{m})$ 玻璃纤维滤膜抽滤; 所得滤液转移至棕色玻璃瓶中低温 $\left(4^{\circ} \mathrm{C}\right)$ 保存, 滤膜用锡䈃 封好在 $-20^{\circ} \mathrm{C}$ 冷冻保存. 所有采样瓶、水样瓶、滤器等容器均预先用 $1: 5$ 的盐酸浸泡 $3 \sim 4 \mathrm{~d}$, 再用去离子水 冲洗干净.

\section{3 样品分析}

1.3.1 POC 和 PON 浓度的测定 在较大的干燥器底部放置一个装有浓盐酸的烧杯, 然后将冷冻的滤膜放在 干燥器的上部熏蒸 $12 \sim 24 \mathrm{~h}$ 以去除颗粒无机碳. 将经浓盐酸熏过的滤膜, 以乙酰苯胺为标准物, 以 EA6000 为催化剂, 氨气为载气, 温度控制在 $975^{\circ} \mathrm{C}$, 于 PE $240 \mathrm{CHN}$ 元素分析仪上同时测定 POC 和 PON 浓度 ${ }^{[20]}$. 


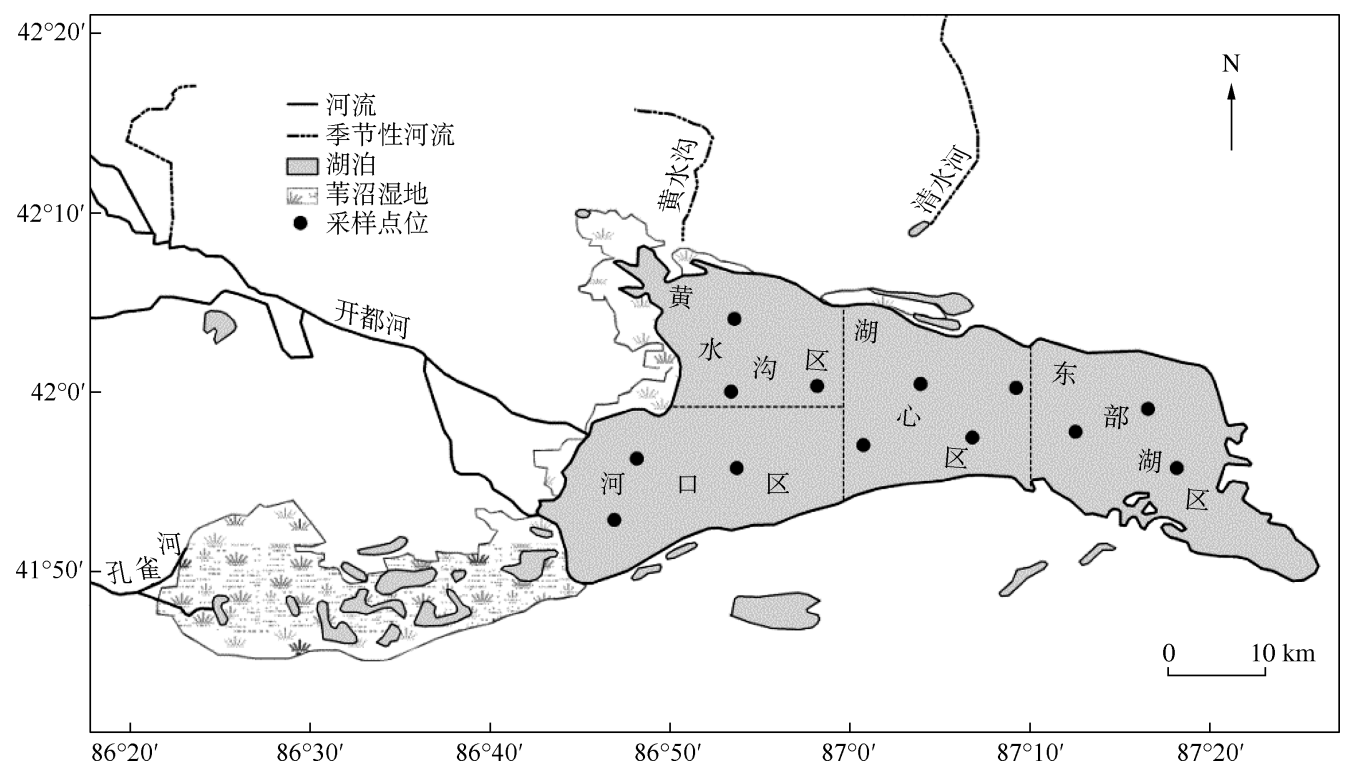

图 1 博斯腾湖采样点分布

Fig. 1 Distribution of sampling sites in Lake Bosten

1.3.2 DOC 浓度的测定 取滤液用高温 $\left(680^{\circ} \mathrm{C}\right.$ ) 催化氧化法 (HTCO), 使用岛津总有机碳分析仪 TOC-V 及 固体试样燃烧装置(SSM-5000A) 测定 DOC 浓度 ${ }^{[23]}$.

1.3.3 Chl. a 浓度的测定 将一张冷冻保存的滤膜迅速解冻后剪碎, 放人匀浆器中, 加人 $6 \sim 8 \mathrm{ml} 90 \%$ 的丙 酮, 在 $500 \sim 1000$ 转/ $\min$ 转速下研磨成糊状后, 倒人离心管中, 再用少许 $90 \%$ 的丙酮冲洗匀浆器 $2 \sim 3$ 次, 将 液体倒人上述离心管中, 使总体积接近于离心管的 $90 \%$, 盖上管塞, 摇匀后置于黑暗低温处静置 $12 \mathrm{~h}$. 然后 离心提取上清液,用分光光度计测定并计算 Chl. a 浓度 ${ }^{[24]}$.

\section{2 结果与分析}

\section{1 博斯腾湖水体 POC 和 DOC 浓度的季节变化}

开都河水体 POC 浓度在春、夏、秋季分别为 $0.51 、 0.67$ 和 $0.14 \mathrm{mg} / \mathrm{L}$. 博斯腾湖水体中 POC 浓度的季节 变化与开都河水体不同, 且各湖区之间也存在一定差异. 就空间分布来看, 各湖区 POC 浓度在春、秋两季空 间差异较小, 但在夏季差异比较大. 河口区 POC 浓度的季节变化与其它湖区不同, 其夏季浓度明显偏高; 东 部湖区表层水体 POC 浓度在春、秋两季均偏低 (分别为 $0.58 、 1.38 \mathrm{mg} / \mathrm{L}$ ), 季节变化相对较小; 湖心区表层 水体和底层水体 POC 浓度的季节变化基本一致, 分别为 $0.64 \sim 1.64 \mathrm{mg} / \mathrm{L}$ 和 $0.65 \sim 1.63 \mathrm{mg} / \mathrm{L}$; 与其它湖区 不同,黄水沟区底层水体 POC 浓度的最低值出现在夏季(图 2).

就全湖平均而言, 表层水体与底层水体 POC 浓度的季节变化相近. 表层水体春、夏、秋季的 POC 平均浓 度分别为 $0.62 、 0.73$ 和 $1.56 \mathrm{mg} / \mathrm{L}$ (表 1). 底层水体 $\mathrm{POC}$ 浓度在春季 $(0.65 \mathrm{mg} / \mathrm{L})$ 和秋季 $(1.60 \mathrm{mg} / \mathrm{L})$ 略高 于表层水体, 但在夏季 $(0.69 \mathrm{mg} / \mathrm{L})$ 却低于表层水体. 虽然秋季 POC 浓度最高, 但夏季 POC 浓度的空间变异 最大(变异系数达 $0.27 \sim 0.31$ ).

开都河和博斯腾湖水体的 DOC 浓度显示了与 POC 浓度不同的季节变化规律和空间分布特征 (图 3). 开都河 水体 DOC 浓度在春、夏、秋季分别为 $2.1 、 1.6 、 0.9 \mathrm{mg} / \mathrm{L}$, 仅为博斯腾湖水体 DOC 浓度的 $9 \% \sim 20 \% .4$ 个湖区水体 DOC 浓度在秋季空间差异很小, 但在春、夏两季有不同程度的差异: 主要特点是河口区 DOC 浓度比其它湖 区明显偏低. DOC 浓度的季节变化规律为: 从春季到夏季 DOC 浓度降低 $1.1 \mathrm{mg} / \mathrm{L}$, 从夏季到秋季增加 1.0 $\mathrm{mg} / \mathrm{L}$. 河口区 DOC 浓度的季节变化最强, 其规律与其它湖区明显不同: 夏季最低, 秋季最高, 秋季比夏季高 $2.4 \mathrm{mg} / \mathrm{L}$. 其它湖区 DOC 浓度在春季最高, 从夏季到秋季的增幅小于 $0.6 \mathrm{mg} / \mathrm{L}$. 


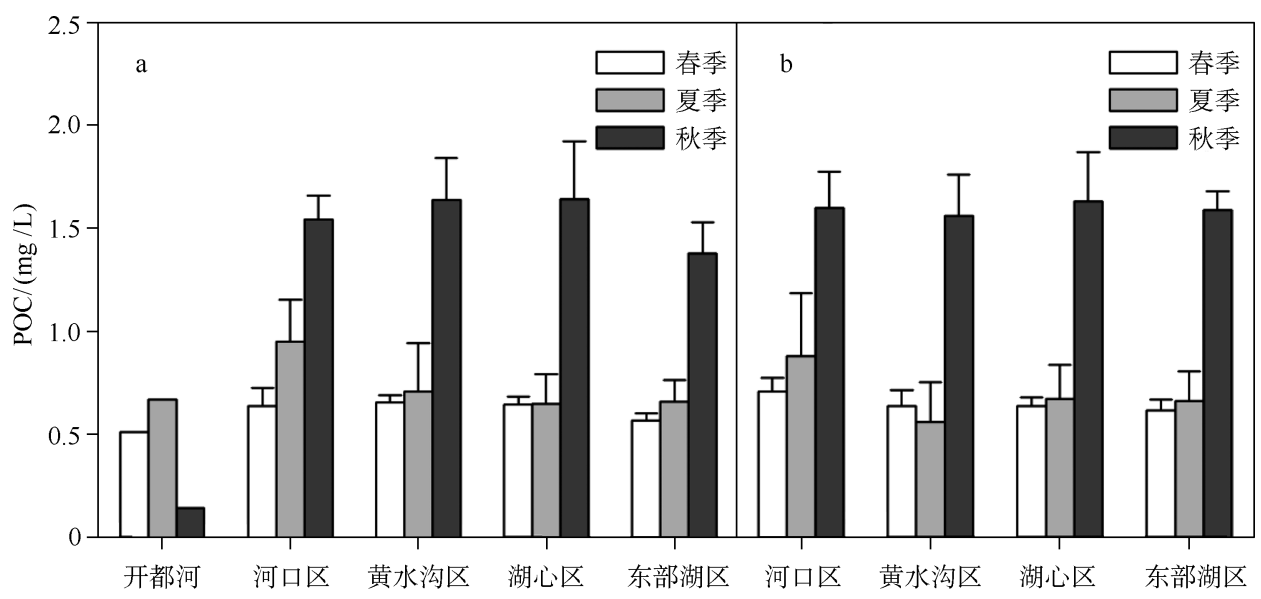

图 2 开都河及各湖区表层 (a) 和底层 (b) 水体 POC 浓度的季节变化

Fig. 2 Seasonal variation of POC concentration in the surface(a) and bottom(b) water of Kaidu River

全湖表层和底层水中 DOC 平均浓度在各季节都非常接近, 差值只有 $0.1 \mathrm{mg} / \mathrm{L}($ 表 1 ). 表层水中 DOC 平 均浓度在春、夏和秋季分别为 $10.30 、 9.30$ 和 $10.20 \mathrm{mg} / \mathrm{L}$. DOC 浓度的空间差异在春、夏两季比较明显(变异 系数均为 0.13 ), 但在秋季很小 (变异系数仅为 0.03 ).

表 1 博斯腾湖春、夏、秋季 POC、DOC 浓度均值及变异系数

Tab. 1 Means and coefficients of variation for POC and DOC concentrations in spring, summer and autumn of Lake Bosten

\begin{tabular}{|c|c|c|c|c|c|c|c|}
\hline \multirow{2}{*}{ 变量 } & & \multicolumn{2}{|c|}{ 春季 } & \multicolumn{2}{|c|}{ 夏季 } & \multicolumn{2}{|c|}{ 秋季 } \\
\hline & & 均值 $/(\mathrm{mg} / \mathrm{L})$ & 变异系数 & 均值 $/(\mathrm{mg} / \mathrm{L})$ & 变异系数 & 均值 $/(\mathrm{mg} / \mathrm{L})$ & 变异系数 \\
\hline \multirow[t]{2}{*}{ POC } & 表层 & 0.62 & 0.09 & 0.73 & 0.27 & 1.56 & 0.14 \\
\hline & 底层 & 0.65 & 0.10 & 0.69 & 0.31 & 1.60 & 0.11 \\
\hline \multirow[t]{2}{*}{ DOC } & 表层 & 10.30 & 0.13 & 9.30 & 0.14 & 10.20 & 0.04 \\
\hline & 底层 & 10.40 & 0.13 & 9.20 & 0.13 & 10.30 & 0.03 \\
\hline
\end{tabular}

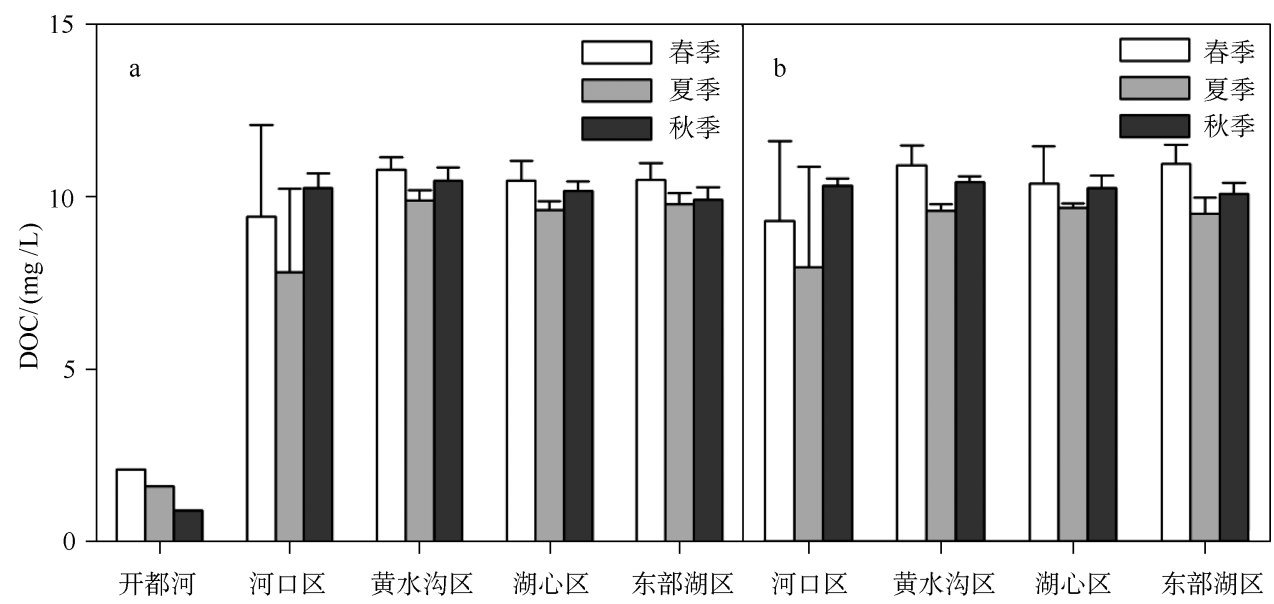

图 3 开都河及各湖区表层水体 (a) 和底层 (b) 水体 DOC 浓度的季节变化

Fig. 3 Seasonal variation of DOC concentration in the surface(a) and bottom(b) water of Kaidu River 开都河水体中 Chl. a 浓度 $(0.46 \sim 0.56 \mu \mathrm{g} / \mathrm{L})$ 明显低于博斯腾湖 $(2.8 \sim 7.4 \mu \mathrm{g} / \mathrm{L})$ (图 4). 就季节变化 
而言, 河口区和东部湖区水体中 Chl. a 浓度变化有很强的季节性, 其夏季浓度远高于春、秋季. 黄水沟区和湖 心区水体中 Chl. a 浓度没有明显的季节变化. 就空间分布来看, 河口区的 Chl. a 浓度在春、秋季最低, 在夏季 最高 $(7.4 \mu \mathrm{g} / \mathrm{L})$; 夏季东部湖区 Chl. a 浓度 $(5.7 \sim 6.8 \mu \mathrm{g} / \mathrm{L})$ 明显高于黄水沟区 $(3.0 \sim 3.3 \mu \mathrm{g} / \mathrm{L})$ 和湖心区 (约 $4.4 \mu \mathrm{g} / \mathrm{L}$ ), 这一结果与赛 - 巴雅尔图等 ${ }^{[20]}$ 的研究基本一致.

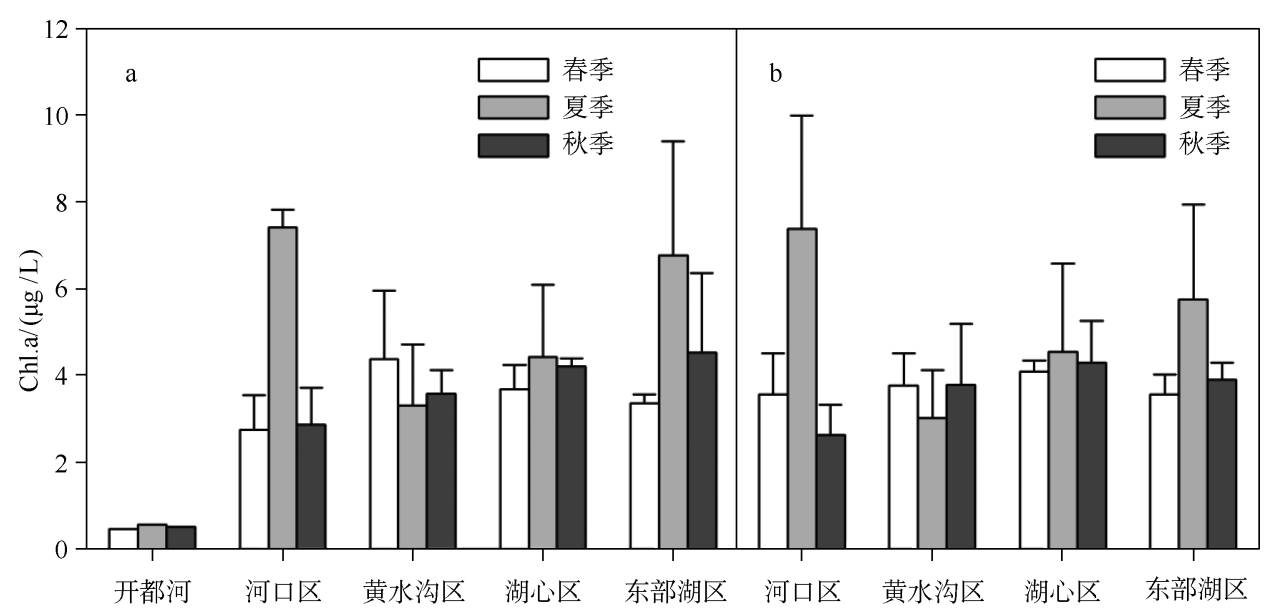

图 4 博斯腾湖各湖区表层 (a) 和底层水体 (b) Chl. a 浓度的季节变化

Fig. 4 Seasonal variation of chlorophyll-a concentration in the surface(a) and bottom(b) water of Lake Bosten

\subsection{POC 和 DOC 的来源分析}

湖泊水体中的有机碳来源分为内源和外源. 其中内源是水体中光合作用的直接和间接产物, 因此与浮 游植物有紧密联系. 浮游植物生物量常用 Chl. a 来反映, 因而, 有机碳与 Chl. a 的相关性及 POC/Chl. a 比常 被用来判断内源的贡献. 另外, 颗粒有机物中的碳氮比 $(\mathrm{C} / \mathrm{N})$ 也可用来判断 POC 的来源. 浮游植物的 $\mathrm{C} / \mathrm{N}$ 一般为 $5 \sim 8$, 而陆源有机物的 $\mathrm{C} / \mathrm{N}$ 比大多超过 $10^{[25]}$. 浮游植物的 POC/Chl. a 介于 $33 \sim 100$ 之间, 如果水体 中 POC/Chl. a 大于 100 , 则表明有较多的陆源输人 ${ }^{[26]}$.

春季博斯腾湖表层和底层水体的 POC 浓度与 Chl. a 浓度不存在显著相关性, POC/Chl. a 变化范围为 $111 \sim 399$ (表层和底层的均值分别为 190 和 177), C/N 变化范围为 $9 \sim 12$ (均值都为 10) (表 2), 这表明春季 博斯腾湖水体的 POC 主要来自外源.

夏季博斯腾湖水体 POC 浓度和 Chl. a 浓度存在一定的相关性 (表 2). 虽然夏季表层水体 POC 浓度与 Chl. a 浓度的相关性较弱 $(r=0.516,0.05<P<0.1)$, 但底层的相关性达到极显著水平 $(r=0.781, P<$ 0.01 ), 这表明夏季博斯腾湖水体 POC 内源贡献比较明显. 但是, 通过 $\mathrm{C} / \mathrm{N}$ 和 POC/Chl. a 的分析发现, 博斯 腾湖夏季水体 $\mathrm{C} / \mathrm{N}$ 变化范围为 $8 \sim 11$ (均值为 $9 \sim 10$ ), $\mathrm{POC} / \mathrm{Chl}$. a 变化范围为 $78 \sim 321$ (均值为 $145 \sim 154$ ), 这说明夏季水体的 POC 也有外源的贡献.

同春季类似,秋季表层水体 POC 浓度和 Chl. a 浓度的相关性很小 $(r=0.211)$; 底层水 POC 浓度和 Chl. a 浓度 具有相关性, 但没有达到显著水平 $(r=0.478,0.05<P<0.1)$ (表 2). 进一步分析发现, 秋季水体中 $\mathrm{C} / \mathrm{N}$ 和 POC/ Chl. a 的比值高于春、夏季, 其变化范围分别为 $5 \sim 13$ 和 $228 \sim 765$, 表明秋季水体的 POC 主要来自外源.

统计分析显示,博斯腾湖春、夏、秋季表层和底层水体的 DOC 浓度与 Chl. a 浓度均不存在显著正相关关系(表 2), 表明博斯腾湖水体 DOC 的变化与浮游植物无直接联系, 可能受内源的影响较小, 而以外部因素的影响为主.

\section{3 讨论和结论}

\section{1 博斯腾湖水体中有机碳含量与国内其它湖泊的比较}

博斯腾湖水体 POC 浓度范围 $(0.6 \sim 1.6 \mathrm{mg} / \mathrm{L})$ 略高于贵州红枫湖的表层水 $(0.5 \sim 1.2 \mathrm{mg} / \mathrm{L})^{[14]}$, 但明显 低于武汉东湖 $(1.1 \sim 9.0 \mathrm{mg} / \mathrm{L})^{[9]}$ 及台湾地区湖泊 $(0.1 \sim 8.4 \mathrm{mg} / \mathrm{L})^{[27]}$. 博斯滕湖水体 DOC 浓度范围 $(9.3 \sim$ 
$10.3 \mathrm{mg} / \mathrm{L}$ ) 远高于阿哈湖、红枫湖和百花湖 (小于 $3.7 \mathrm{mg} / \mathrm{L})^{[28-29]}$, 但明显低于武汉东湖 $(7 \sim 22 \mathrm{mg} / \mathrm{L})^{[9]}$ 和 内蒙地区的岱海 $(5 \sim 38 \mathrm{mg} / \mathrm{L})^{[30]}$.

表 2 博斯腾湖表层和底层水体颗粒有机碳 C/N、POC/Chl. a 及 POC、DOC 与 Chl. a 的相关性

Tab. 2 Ranges (means) of $\mathrm{C} / \mathrm{N}$ and POC/Chl. a ratios and correlations between POC, DOC and Chl. a in the surface and bottom water of Lake Bosten

\begin{tabular}{cccccc}
\hline \multirow{2}{*}{ 季节 } & $\begin{array}{c}\mathrm{C} / \mathrm{N} \\
\text { 范围 (均值) }\end{array}$ & $\begin{array}{c}\text { POC/Chl. a } \\
\text { 范围 (均值) }\end{array}$ & $\begin{array}{c}\text { POC 与 Chl. a 的 } \\
\text { 相关系数 }\end{array}$ & $\begin{array}{c}\text { DOC 与 Chl. a 的 } \\
\text { 相关系数 }\end{array}$ \\
\hline \multirow{2}{*}{ 春季 } & $9 \sim 12(10)$ & $111 \sim 399(190)$ & 0.105 & 0.193 \\
& 表层 & $9 \sim 11(10)$ & $144 \sim 231(177)$ & 0.443 & 0.258 \\
夏季 & 底层 & $8 \sim 11(10)$ & $78 \sim 321(154)$ & 0.516 & -0.432 \\
& 表层 & $8 \sim 10(9)$ & $97 \sim 214(145)$ & $0.781^{* *}$ & -0.089 \\
秋季 & 底层 & $11 \sim 13(12)$ & $228 \sim 748(432)$ & 0.211 & $-0.589^{*}$ \\
& 表层 & $5 \sim 13(12)$ & $294 \sim 765(469)$ & 0.478 & -0.246 \\
\hline
\end{tabular}

*表示显著相关, $P<0.05 ; * *$ 表示极显著相关, $P<0.01$.

这些湖泊水体中有机碳浓度的差异可能与湖泊的富营养化程度有关. 一般来说, 湖水中富营养化程度 越高, 其内部生物化学过程越强, 有机碳浓度越高. 东湖和岱海受人类活动影响较大, 富营养化程度较高, 因 而 POC、DOC 浓度偏高; 而红枫湖和百花湖受人类活动影响小, 不仅外源贡献小, 同时因为富营养化程度低, 其内部生物化学过程弱, 因而导致 POC、DOC 浓度偏低.

\section{2 博斯腾湖水体浮游生物的季节变化}

已有研究显示, 博斯腾湖水体中浮游植物和动物的生物量有很强的季节性: 浮游植物生物量最高值出 现在夏季 ${ }^{[18]}$, 而浮游动物生物量最高值出现在 $8 、 9$ 月 ${ }^{[19]}$. 赖英 ${ }^{[18]}$ 的研究表明, 浮游植物秋季生物量与夏季 相近, 而春季的生物量只有夏季的 5\% 40\% . 本研究发现, 博斯腾湖 Chl. a 含量仅在河口区和东部湖区有与 浮游植物相似的季节变化; 黄水沟区夏季 Chl. a 浓度明显低于其它季节. 赛 - 巴雅尔图等的研究显示 Chl. a 浓度的变化与营养盐含量没有直接关系 ${ }^{[20]}$. 这些研究表明, 博斯腾湖水体中 Chl. a 浓度与浮游植物的生物 量可能不存在线性关系.

\section{3 博斯腾湖水体 POC 浓度的季节变化}

本研究发现,博斯腾湖水体 POC 浓度的季节变化非常明显: 秋季 POC 的平均浓度分别是夏季和春季的 2.2 倍和 2.5 倍. 本文的研究结果与国内一些研究不一致. 比如, 武汉东湖水体 POC 浓度的最大值出现在冬 季 ${ }^{[9]}$, 贵州红枫湖的 POC 浓度在夏季较高 ${ }^{[14]}$.

这些湖泊水体中 POC 浓度季节变化的不同可能与其来源有关. 比如,红枫湖的有机物大部分来自光合 作用 ${ }^{[14]}$, 所以 POC 浓度的高值出现在浮游植物丰富的夏季. 而本文的分析表明, 博斯腾湖水体的 POC 在 2012 年春季和秋季可能主要来自外源, 与水体内部的生物化学过程无直接关系. 尤其是在 2012 年秋季, 博 斯腾湖整个湖面 (包括远离河口的东部湖区) 出现了高浓度的 POC (约 $1.5 \mathrm{mg} / \mathrm{L}$ ), 并且 POC/Chl. a 高达 $228 \sim 765$, 说明有大量来源于非浮游生物物质的贡献. 然而, 房传苓等在 2011 年秋季的观测显示, 博斯腾湖 湖周水体中 POC 浓度在 $0.3 \sim 1.0 \mathrm{mg} / \mathrm{L}$ 范围内 ${ }^{[21]}$, 明显低于 2012 年秋季. 这些结果的不一致性可能反映 了年季之间的差异,因而,博斯腾湖水体 POC 浓度的季节变化及其主控因素有待进一步深人研究.

\section{4 博斯腾湖水体 DOC 浓度的季节变化}

博斯腾湖水体 DOC 浓度的季节变化与 POC 明显不同. 总体上看, DOC 浓度在夏季低于春、秋两季,这与 红枫湖 DOC 浓度的季节变化不同. 有研究表明,红枫湖水体 DOC 浓度的最大值出现在春末夏初或夏季,与 叶绿素 a 含量的季节变化具有同步性 ${ }^{[28-31]}$. 而博斯腾湖水体中 DOC 与叶绿素 a 浓度不存在相关性, 说明内 源的直接贡献可能很小. 博斯腾湖 DOC 浓度从春季到夏季有不同程度的下降, 说明水体中的 DOC 在此期间 由于温度的增加, 分解超过累积. 开都河径流从春季到夏季显著增加 ${ }^{[32]}$, 河水中的 DOC 浓度仅为 $0.9 \sim$ $2.1 \mathrm{mg} / \mathrm{L}$ (图 3). 本研究显示, 河口区 DOC 浓度在夏季最低, 这说明开都河河水的输人对这一湖区有一定的 稀释作用. 博斯腾湖水体 DOC 浓度在秋季高于夏季, 反映了累积多于分解, 其累积过程可能与 POC 的大量 
增加有关, 部分外源有机碳属于溶解性的. 与 POC 不同, DOC 浓度的年季变化相对较小 (表 1$)^{[21]}$.

\section{4 参考文献}

[ 1 ] 王苏民,窦鸿身. 中国湖泊志. 北京:科学出版社,1998.

[ 2] 吴庆龙, 邢 鹏, 李化炳等. 草藻型稳态转换对湖泊微生物结构及其碳循环功能的影响. 微生物学通报, 2013,40 (1) : 87-97.

[ 3 ] 陈泮勤. 地球系统碳循环. 北京:科学出版社, 2004 .

[ 4 ] Yoshioka T, Ueda S, Khodzher T et al. Distribution of dissolved organic carbon in Lake Baikal and its watershed. Limnology, $2002,3:$ : 159-168.

[ 5 ] Dickens AF, Baldock J, Kenna TC et al. A depositional history of particulate organic carbon in a floodplain lake from the lower Ob’ River, Siberia. Geochimica et Cosmochimica Acta, 2011, 75(17) : 4796-4815.

[ 6 ] Jiao NZ, Herndl GJ, Hansell DA et al. Microbial production of recalcitrant dissolved organic matter: long-term carbon storage in the global ocean. Nature Reviews Microbiology, 2010, 8(8) : 593-599.

[ 7 ] McNichol AP, Aluwihare LI. The power of radiocarbon in biogeochemical studies of the marine carbon cycle: Insights from studies of dissolved and particulate organic carbon( DOC and POC). Chemical Reviews, 2007, 107: 443-466.

[ 8 ] Hori T, Sugiyama Y, Sugiyama M. Chemical and physicochemical characteristics of dissolved organic carbon circulating in harmonic lake Biwa. Japanese Journal of Limnology, 1998, 59:39-52.

[ 9 ] Liu XJ, Xu XQ, Xie P. Seasonal changes of dissolved and particulate organic carbon in Donghu Lake, China. Chinese Journal of Oceanology and Limnology, 2000, 18(4) : 372-377.

[10］杨顶田,陈伟民. 长江下游湖泊中可溶性有机碳的时空分布. 环境污染与防治,2004,26(4):275-278.

[11 ] Dunalska J, Gorniak D, Teodorowicz M et al. Seasonal distribution of dissolved and particulate organic carbon in the water column of a meromictic lake. Polish Journal of Environmental Studies, 2004, 13: 375-379.

[12] Bade DL, Carpenter SR, Cole JJ et al. Sources and fates of dissolved organic carbon in lakes as determined by whole-lake carbon isotope additions. Biogeochemistry, 2007, 84: 115-129.

[13 ] Laybourn-Parry J, Madan NJ, Marshall WA et al. Carbon dynamics in an ultra-oligotrophic epishelf lake(Beaver Lake, Antarctica) in summer. Freshwater Biology, 2006, 51(6): 1116-1130.

[14] 刘丛强.生物地球化学过程与地表物质循环:西南喀斯特流域侵蚀与生源要素循环. 北京:科学出版社,2007.

[15] 钟瑞森,董新光. 新疆博斯腾湖水盐平衡及水环境预测. 湖泊科学,2008,20(1):58-64.

[16] 谢贵娟, 张建平, 汤祥明等. 博斯腾湖水质现状 (2010-2011 年) 及近 50 年来演变趋势. 湖泊科学, 2011,23 (6) : 837-846.

[17] 马 锦,张 珉. 从溶解氧含量变化分析博斯腾湖水质现状. 干旱环境监测 , 2007,21(2):92-96.

[18] 赖 英. 博斯腾湖浮游植物季节变化的研究. 水生态学杂志, 2009,2 (5):103-105.

[19] 王松波,薛庆举,高 光等. 新疆博斯腾湖浮游甲壳动物群落结构. 湖泊科学, 2011,23(6):926-933.

[20] 赛. 巴雅尔图, 黄 瑾, 谢贵娟等. 新疆博斯腾湖浮游细菌丰度对富营养化及咸化的响应. 湖泊科学, 2011,23(6): 934-941.

[21] 房传苓,王秀君,王家平. 新疆博斯腾湖湖周水体碳和盐离子的空间分布. 干早区研究,2013,30(2):226-230.

[22] 夏 军. 博斯腾湖水资源可持续利用——理论·方法・实践. 北京: 科学出版社,2003.

[23 ] Sharp JH, Benner R, Bennett L et al. Analyses of dissolved organic carbon in seawater: the JGOFS EqPac methods comparison. Marine Chemistry, 1995, 48(2):91-108.

[24] Grasshoff K, Kremling K, Ehrharht M. Methods of seawater analysis. Wiley Online Library, 1999: 201-223.

[25] Kendall C, Silva SR, Kelly VJ. Carbon and nitrogen isotopic compositions of particulate organic matter in four large river systems across the United States. Hydrological Processes, 2001, 15(7) : 1301-1346.

[26] Welschmeyer NA, Lorenzen CJ. Chlorophyll budgets: zooplankton grazing and phytoplankton growth in a temperate fjord and the central Pacific Ocean. Limnology and Oceanography, 1985,30(1):1-21.

[27] 黄炳达, 陈镇东. 台湾地区湖泊水库悬浮颗粒有机质之碳、氢、氧、氮、硫元素计量分析. 海洋与湖沼, 1994, (1): 29-37.

[28 ] Li W, Wu FC, Liu CQ et al. Temporal and spatial distributions of dissolved organic carbon and nitrogen in two small lakes on the Southwestern China Plateau. Limnology, 2008, 9(2) : 163-171.

[29] 宋柳霆, 王中良, 滕彦国等. 贵州阿哈湖物质循环过程的微量元素地球化学初步研究. 地球与环境, 2012,287 (1): 9-17.

[30］吕昌伟,何 江,梁英等.乌梁素海和岱海上覆水中碳的形态分布及其制约机制. 农业环境科学学报, 2010,174 (2) :330-338.

[31] 黎 文, 吴丰昌, 傅平青等. 贵州红枫湖水体溶解有机质的剖面特征和季节变化. 环境科学, 2006, 27 (10): 1979-1985.

[32] 王维霞,王秀君,姜逢清等. 开都河近 30a 来 4-9 月径流量变化的气候响应. 干旱区研究,2013,30(4):743-748. 